\title{
Risk attitudes in a social context
}

\author{
Ingrid M. T. Rohde • Kirsten I. M. Rohde
}

Published online: 20 October 2011

(C) The Author(s) 2011. This article is published with open access at Springerlink.com

\begin{abstract}
Many experiments have demonstrated that when evaluating payoffs, people take not only their own payoffs into account, but also the payoffs of others in their social environment. Most of this evidence is found in settings where payoffs are riskless. It is plausible that if people care about the payoffs of others, they do so not only in a riskless context, but also in a risky one. This suggests that an individual's decision making under risk depends on the risks others in his or her environment face. This paper is the first to test whether individuals' risk attitudes are affected by the risks others face. The results show that risk attitudes appear to be less affected by others' risks than expected, even though the same subjects do show concerns for inequality in a riskless setting. Interestingly, we find that people prefer risks to be independent across individuals in society rather than correlated.
\end{abstract}

There is ample evidence that people care not only about their own payoffs, but also about the payoffs of others (Fehr and Schmidt 2002; Sobel 2005).

Kirsten Rohde's research was made possible through a VENI grant from the Netherlands Organization for Scientific Research (NWO). The authors would like to thank Aurélien Baillon, Jona Linde, Arno Riedl, Joep Sonnemans, Martin Strobel, and Peter P. Wakker for helpful comments. Special thanks go to Burak Can who helped conducting the experiments and shaping our ideas.

I. M. T. Rohde

Faculty of Health, Medicine and Life Sciences, Maastricht University, P.O. Box 616, 6200 MD Maastricht, The Netherlands

\section{K. I. M. Rohde $(\bowtie)$}

Erasmus School of Economics, H13-25, Erasmus University Rotterdam, P.O. Box 1738, 3000 DR Rotterdam, The Netherlands

e-mail:rohde@ese.eur.nl 
Many experiments have demonstrated that people show concerns for the fairness of income allocations. In general, people especially dislike being worse off than others: they try to 'keep up with the Joneses' (Galí 1994). In line with prospect theory (Kahneman and Tversky 1979) these results suggest that people evaluate their own payoffs relative to a reference point, where in these social contexts the payoffs of others serve as a reference point.

Most studies showing that people care about the income of others in society, assume that the incomes of all involved are certain, i.e. they abstract from risk. Extrapolating the results of these studies to a risky context suggests that people also care about the payoffs of others when payoffs are risky. It is therefore to be expected that payoffs of others serve as a reference point not only in a risk free context, but also in a risky one.

From prospect theory in individual decision making we know that if an individual is asked to choose between two lotteries, his choice will depend on his reference point: a different reference point may lead to a different choice. Translating this to a social context, and assuming that the reference point is at least partly determined by the payoffs of others, we expect that the payoffs of others have an impact on the choices people make between lotteries that affect only themselves. Thus, we posit that people's choices between lotteries are not only affected by the lotteries themselves, but also by the payoffs and lotteries others face. In other words, people's risk attitudes are likely to depend on the payoffs and lotteries others face. To stress this dependency, we refer to risk attitudes as social risk attitudes. In this paper we do a first test to analyze to what extent risk attitudes indeed are social risk attitudes.

Knowing how individuals' attitudes towards risk are affected by the payoffs and risks faced by people around them may yield important insights into behavior in financial markets, and, for instance, behavior in times of a pandemic. ${ }^{1}$ If risk attitudes are affected by risks faced by the environment, financial booms and crises do not only directly affect investment behavior, but also indirectly, through their impact on risks faced by others. Similarly, a pandemic will not only have a direct, but also an indirect impact on behavior.

In an experiment we let subjects make risky choices in a social context. The risky social context is operationalized by letting subjects choose between allocation lotteries that determine both the lottery they themselves face and the lotteries the other ten participants in the experimental session face. We ask subjects to choose between two lotteries for themselves, while keeping the other subjects' lotteries fixed. By repeating the same question for various lotteries for the other subjects, we can explore whether the lotteries that others face affect the decision maker's choices. We hypothesize that varying those lotteries will affect choices. We refer to these questions as individual risk questions. We also included questions where subjects choose between lotteries

\footnotetext{
${ }^{1}$ Evidence suggests that in financial markets and in pandemics, risk attitudes are influenced by a type of social contagion (e.g. see Christakis and Fowler 2007; Shiller 2008).
} 
for the other subjects while keeping their own lottery fixed. We refer to these questions as peer risk questions.

An attractive feature of our individual risk questions is that they allow us to investigate how distributions of risks and payoffs for the other subjects influence risky choice, by excluding any emotions and motives related to social interactions, such as group compliance or avoiding the feeling of guilt. The choices in this type of question are not confounded by adherence to social norms, feelings of social pressure, or fear for reciprocal behavior.

In the peer risk questions subjects choose between, for instance, (1) an allocation where every 'other subject' receives an independent lottery yielding 20 euro with $30 \%$ probability and 10 euro otherwise, and (2) an allocation yielding 20 euro to $30 \%$ of the other subjects and 10 euro to the rest of the other subjects. We refer to the first option as a "lottery" and to the latter as the "corresponding allocation." The expected value and the possible outcomes are the same in both options. There is one crucial difference between the options, though: in the "lottery" risks are perfectly independent across subjects, whereas in the "allocation" risks are correlated. A choice between these options sheds light on our experience of facing risks of natural disasters, influenza pandemics, terrorist attacks, and airplane crashes, where risks show a strong correlation with others in our environment, compared to events with similar, but uncorrelated risks.

Our results are mixed. We find relatively weak evidence for the lotteries of others to influence a subject's choice between lotteries for himself even though almost all subjects exhibit behavior consistent with social preferences when they can only influence others' payoffs. Nevertheless, the evidence does suggest several behavioral patterns, such as avoidance of inequality whenever possible. The results of the peer risk questions are striking and show a clear preference for the lottery rather than for the corresponding allocation, suggesting that subjects prefer situations where risks are independent rather than correlated.

The paper proceeds as follows. Section 1 introduces our experimental design to measure risk preferences in a social context. Sections 2 and 3 discuss the experiment and report its results. Finally, Sections 4 and 5 provide a discussion and interpretation of the results of the experiment and a conclusion.

\section{Experimental design}

The experiment consists of two types of questions: peer risk questions and individual risk questions. Subjects make choices between allocation lotteries. An allocation lottery is a lottery over allocations of money over a group of subjects.

\subsection{Individual risk questions}

Individual risk questions are designed to study social risk attitudes. We consider a group of subjects and let each person choose between two lotteries 
while fixing the lotteries that the others in the group receive, i.e. we let each subject choose between allocation lotteries that differ only in the lottery the subject himself receives. Thus, when choosing, the decision maker cannot influence the payoffs and risks of the other subjects in the group. While the payoffs and risks of other subjects cannot be influenced, this does not mean that they play no role. From the literature on social preferences (Sobel 2005) we know that people evaluate allocations of money by taking into account not only their own payoffs, but also the payoffs of others, often their peers. This finding suggests that, when evaluating lotteries for themselves, people do take into account the lotteries others face. Our individual risk questions will allow us to analyze the extent to which risk attitudes depend on the lotteries others face.

\subsection{Peer risk questions}

In order to ensure sufficient variation in questions and to reduce the risk of subjects ignoring lotteries of others merely to reduce cognitive burden during the experiment, we also included another type of questions where the decision maker could influence only the lotteries of others. In peer risk questions we fix the lottery that the decision maker will receive and let him choose between allocation lotteries for the other individuals in the group. In these questions we mostly focus on different types of allocation lotteries. Each type of allocation lottery can be seen as a different allocation rule, where the decision maker acts as a social planner. We let subjects choose between, for instance, an allocation where each 'other subject' receives an independent lottery yielding 20 euro with $30 \%$ probability and 10 euro otherwise, and an allocation yielding 20 euro to $30 \%$ of the other subjects and 10 euro to the rest of the other subjects. We refer to the first option as a lottery and to the latter as the corresponding allocation. In the latter, the subjects receiving a particular payoff will be randomly determined, so that every subject still has $30 \%$ probability of receiving 20 euro and $70 \%$ probability of receiving 10 euro. The resolution of the latter lottery, however, is not independent across subjects. The appeal of this type of question is that it indicates how subjects care about the correlation of their payoffs and risks with the payoffs and risks of others.

This type of question also indicates how concerns for procedural fairness may arise. If subjects would prefer the lottery to the corresponding allocation, then they prefer to let fate determine the final payoffs as much as possible and prefer to give everybody an equal chance on payoffs, independently of what the others receive. A preference for the lottery over the corresponding distribution received considerable attention in the literature on social risk analysis in the 1980's (e.g. Broome 1982; Fishburn 1984; Hammerton et al. 1982; Keeney 1980; Keller and Sarin 1988). Our peer risk questions allow us to test whether the mentioned findings in the 1980's are robust to real incentives.

A nice illustration of preferences over allocation rules is the following case in the Supreme Court of the United States: Holmes v. United States (Broome 
1984). In 1841, an American ship struck an iceberg close to Newfoundland. The crew and half of the passengers managed to escape in two available lifeboats. One of these lifeboats was overcrowded. In a desperate attempt to keep this lifeboat from sinking, the crew members threw persons overboard by using the criteria that no woman would be thrown overboard and that no couples would be separated. Crewman Alexander Holmes was later on convicted of 'unlawful homicide' and was sentenced to jail by the judge. The interesting aspect of this story is that Holmes was not convicted because of the manslaughter but rather because of the fact that he had not cast lots: "In no other than this or some like way are those having equal rights put upon equal footing ..." The council, however, argued that the principle of selection the crewman used was more humane than using lots. The council and the crewman, thus, had different preferences over allocation rules than the judge.

\section{Experiment}

All experimental sessions were conducted at the Behavioral and Experimental Economics laboratory Maastricht (BEELab) with 121 (65 male, 56 female) students from Maastricht University. The vast majority (88\%) were students from Economics and Business Administration. The other subjects were students from Law, Cultural Sciences, and from University College Maastricht. They were recruited through email announcements and announcements on the students' intranet. Each subject participated in only one session. The experiment was programmed in Z-tree (Fischbacher 2007).

In every session, exactly 11 subjects participated. They all received a showup fee of 4 euro. The average earnings per subject, including this show-up fee, were 12.98 euro. The experiment lasted $70 \mathrm{~min}$ on average. Between 20 and 35 min were spent on reading the instructions. At the end of the instructions there was a short questionnaire to test whether subjects understood the instructions. The experiment would continue only after all subjects understood the instructions. The instructions can be found in Appendix B. At the end of the experiment subjects were asked to answer some demographic questions.

In reality individuals compare themselves with many others: friends, colleagues, neighbors, family, etc. In order to replicate the situation of one individual comparing himself with many others, we let subjects compare themselves not with only one other subject, but with all other subjects in the same session. Thus, when a subject makes a decision, there are ten others.

The experiment consisted of 40 questions where subjects had to make choices between allocation lotteries. There were 28 individual risk questions and 12 peer risk questions. At the start of the experiment three practice questions were given. The order of the other 40 questions was randomized. We also randomized the left-right presentation on the screen. To determine the earnings of all subjects, at the end of each session one of the subjects and one of his questions was chosen at random. If this implied that the other subjects 
would receive a lottery, the lottery was played for each of these subjects independently.

The allocation lotteries to choose from were displayed on the computer screen as in Fig. 3 in Appendix A. The allocation lotteries are displayed as a $2 \times 2$ matrix. The columns represent the different allocation lotteries, where the upper half shows the lottery for the decision maker. In order to avoid biases, we randomize the order of all 40 questions.

\subsection{Individual risk questions}

The 28 individual risk questions are given in Tables 3, 4, and 5 in Appendix A. The columns 'lottery 1' and 'lottery 2' give the two lotteries between which the decision maker has to choose given that the other 10 subjects receive the lottery described in the third column. The subjects are offered 4 types of choices. In the first type of choice the subject chooses between $(30 \%: 23,70 \%$ $: 3)^{2}$ and 10 for sure for himself. As in this question one of the lotteries is a payoff to be received with certainty, we label this type of question 'Certainty'. The second type of choice is between (40\%:13, 60\%:8) and (50\%:20,50\% $: 0)$ for the decision maker. Here the latter is a mean preserving spread (MPS) of the former, which is why we label these questions 'MPS'. The third type of choice is between $(80 \%: 12,20 \%: 2)$ and $(80 \%: 7,20 \%: 22)$. Neither of these two is a MPS of the other. An important difference between these lotteries is the minimum payoff attainable, which the subjects may choose to maximize. Therefore, we label this type of question 'Maximin'. We added two questions with higher stakes where the subjects choose between $(20 \%: 60,80 \%: 0)$ and (40\%: 13, 60\% : 8). We label these two questions 'Maximin High Stakes'.

For each of the four types of questions we varied the lotteries that the other subjects received in order to check whether this would influence decisions. Some lotteries would ensure the same payoff as the decision maker, others would ensure the same lottery. Furthermore, we varied the lotteries the others would receive with respect to the probabilities and payoffs. By varying the lotteries the others receive, we can infer whether the levels of risk and the levels of payoffs others receive influence the decision maker's risk attitude. We ask different types of questions in order to obtain richness in the data that allows us to explore the basic patterns of behavior that can be observed in a risky social environment.

As a benchmark, in each of the three categories, Certainty, MPS, and Maximin, we have one question where the other subjects receive the same payoff as the decision maker. In that question, the resulting allocation would always be constant, i.e. without any inequality. This question, therefore, reveals subjects' risk attitudes in isolation, i.e. if there would be no others. A similar question,

\footnotetext{
${ }^{2}(p: x, 1-p: y)$ denotes the lottery yielding $x$ with probability $p$ and $y$ with probability $1-p$.
} 
which does allow for inequality in final allocations, is the one where the other subjects receive the same lottery as the decision maker, but where this lottery is independently resolved for each subject. A subject only concerned with ex ante opportunities of others would not behave differently in this question compared to the benchmark question. Subjects who are concerned with the equality of final allocations might behave differently, though.

For the other questions we varied the payoff and risks of the other subjects' lottery. In some questions the others would always receive more than the decision maker. In other questions, they would always receive less. There are also questions where the others would receive outcomes that are between the maximum and the minimum of what the decision maker would get. Finally, there are questions, like C6, that are of the lottery type as discussed in the description of peer risk questions and there are questions of the corresponding allocation type, like C7. Note that in $\mathrm{C} 7$ the subjects who would receive 15 would be determined randomly.

\subsection{Peer risk questions}

Table 6 in Appendix A lists the peer risk questions. In questions P1, P3, and P7 subjects are asked to choose between a lottery and the corresponding allocation. Questions P2, P4, and P5 illustrate whether the lotteries of the decision maker in $\mathrm{P} 1, \mathrm{P} 3$, and $\mathrm{P} 7$ are considered to be better or worse than the lottery that guarantees equality. We added P6 to test for consistency, as the answer in $\mathrm{P} 5$ and $\mathrm{P} 7$ would, together with transitivity, predict the answer in P6. P8, P9, and P10 test whether subjects are concerned with equality among the others. Finally, P11 and P12 test whether subjects like to be ahead of others and whether they dislike others being ahead.

\subsection{Demographic questions}

At the end of the experiment, we asked subjects for their age, gender, number of brothers, and number of sisters. We also asked what kind of study programme they are enrolled in: Economics, Psychology, Healthcare, or other. Finally, we asked whether they are a member of a study- or student association, whether they are a member of a sports club, and how many subjects in their session they know.

\subsection{Relation with Dictator and Ultimatum games}

In most of the literature the way to analyze social preferences is to let people play a game such as a dictator game or an ultimatum game (Bolton et al. 2005; Charness and Rabin 2002; Karni et al. 2008; Sebald 2007; Trautmann 2009). The driving forces of decisions in the ultimatum game are not only preferences over final allocations, but also reciprocity concerns: people may behave in a 
certain way to induce others to behave in a certain way. It may well be that a social norm and reciprocity concerns conflict with a person's preferences over final allocations, which makes it impossible to disentangle preferences over final allocations from reciprocity concerns in the existing experiments. Reciprocity is not present in one-stage games. Therefore, one can argue that in the dictator game reciprocity plays no role. As we are interested in preferences over final allocations rather than reciprocity concerns, the dictator game might be more suitable for our purposes than the ultimatum game.

The decisions subjects make in dictator games, however, always simultaneously influence both their own payoff and the payoff of at least one other player. Therefore, these dictator games and their risky versions (e.g. Bohnet and Zeckhauser 2004; Bohnet et al. 2008; Boles and Messick 1995; Bolton and Ockenfels 2010) would only allow us to analyze the tradeoff subjects make between (1) individual risks and payoffs and (2) others' risks and payoffs, and would not allow us to study the impact of risks and payoffs of others on attitudes towards individual risks and payoffs. This is why we deliberately chose not to implement a risky version of the dictator game.

\section{Results}

\subsection{Individual risk questions}

In the Certainty and MPS questions, the majority of the choices $(79.75 \%$ and $82.19 \%$, respectively) are in accordance with risk aversion, and in the Maximin questions the majority of choices $(73.56 \%)$ is in accordance with maximin. The exact percentages of the choices for each question can be found in Table 7 in Appendix A. These results are in accordance with the choices we would expect from subjects in an isolated context. Thus, the social context provided here does not seem to strongly influence subjects' risk attitudes.

Although in the Certainty, MPS, and Maximin questions subjects often chose one particular lottery, they did not always choose that lottery. This suggests that there were questions that made subject's preferences switch when changing the lottery that others would receive. These switches can be caused by random error, but also by the social component of preferences being strong enough to make preferences between lotteries switch. In order to test whether switches are mainly random or clearly in favor of one or the other lottery, we used a sign test. Figure 1 shows which switches are significant and in which direction. An arrow from $\mathrm{C} 1$ to $\mathrm{C} 4$ indicates that most switches from $\mathrm{C} 1$ to $\mathrm{C} 4$ were from lottery 1 to lottery 2 . Thick arrows indicate significance at a $5 \%$ level (one-sided), and the other arrows indicate significance at the $10 \%$ level. Table 1 gives the corresponding $\mathrm{p}$-values.

We also examined the effects of demographic and individual characteristics on the choice behavior. For each characteristic, we calculated per block (i.e. C, MPS, MM, MMH) the number of times one particular lottery was chosen, 


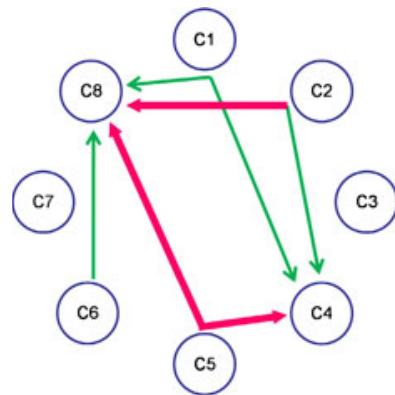

(a) Certainty

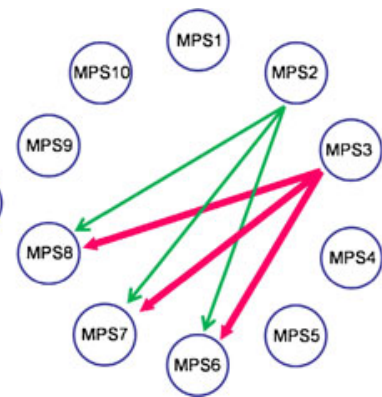

(b) Mean Preserving Spread

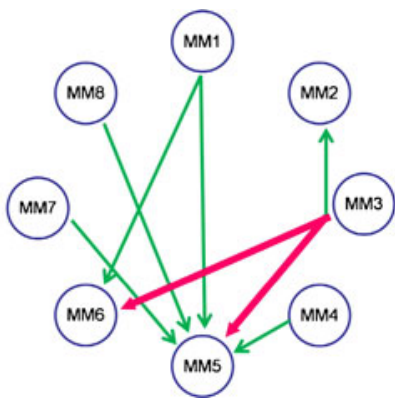

(c) Maximin

Fig. 1 Significant switches from lottery 1 to lottery 2

and ran a Mann Whitney $U$ test on these values. We found no significant effects, except for male subjects choosing lottery 1 significantly more often than female subjects in MMH (MWU: $\mathrm{p}=0.001$, two-sided). Thus, men seem more sensitive to higher stakes than women.

\subsection{Peer risk questions}

The choices in questions $\mathrm{P} 1, \mathrm{P} 3$, and $\mathrm{P} 7$ reveal that subjects have a significant preference for the lottery rather than the corresponding allocation (signtest: $\mathrm{p}<0.001$, two-sided). This holds for all three questions. In P1, 67.77\% of the subjects choose the lottery. In P3 and P7 these percentages are $67.77 \%$ and $82.64 \%$, respectively. The exact percentages of the choices for all peer risk questions can be found in Table 8 in Appendix A.

For each subject, we counted the number of times he or she chose the lottery in P1, P3, and P7. Figure 2 summarizes the results. We observe that a vast number of subjects chose the lottery in a majority of the questions. In order to

Table 1 Significance of switches (one-sided p-values)

\begin{tabular}{|c|c|c|c|c|c|}
\hline \multicolumn{6}{|c|}{ Significant switches from lottery 1 to lottery 2} \\
\hline \multicolumn{2}{|c|}{ Certainty } & \multicolumn{2}{|c|}{ Mean preserving spread } & \multicolumn{2}{|l|}{ Maximin } \\
\hline Switch & $\mathrm{p}$-value & Switch & p-value & Switch & p-value \\
\hline $\mathrm{C} 1 \rightarrow \mathrm{C} 4$ & 0.095 & MPS2 $\rightarrow$ MPS6 & 0.073 & MM1 $\rightarrow$ MM5 & 0.067 \\
\hline $\mathrm{C} 1 \rightarrow \mathrm{C} 8$ & 0.068 & MPS2 $\rightarrow$ MPS7 & 0.067 & $\mathrm{MM} 1 \rightarrow \mathrm{MM} 6$ & 0.084 \\
\hline $\mathrm{C} 2 \rightarrow \mathrm{C} 4$ & 0.058 & MPS2 $\rightarrow$ MPS8 & 0.058 & $\mathrm{MM} 3 \rightarrow \mathrm{MM} 2$ & 0.067 \\
\hline $\mathrm{C} 2 \rightarrow \mathrm{C} 8$ & 0.032 & MPS3 $\rightarrow$ MPS6 & 0.033 & $\mathrm{MM} 3 \rightarrow \mathrm{MM} 5$ & 0.014 \\
\hline $\mathrm{C} 5 \rightarrow \mathrm{C} 4$ & 0.032 & MPS3 $\rightarrow$ MPS7 & 0.047 & $\mathrm{MM} 3 \rightarrow \mathrm{MM} 6$ & 0.035 \\
\hline $\mathrm{C} 5 \rightarrow \mathrm{C} 8$ & 0.013 & MPS3 $\rightarrow$ MPS8 & 0.032 & MM4 $\rightarrow$ MM5 & 0.072 \\
\hline \multirow[t]{2}{*}{$\mathrm{C} 6 \rightarrow \mathrm{C} 8$} & 0.095 & & & $\mathrm{MM} 7 \rightarrow \mathrm{MM} 5$ & 0.084 \\
\hline & & & & MM8 $\rightarrow$ MM5 & 0.084 \\
\hline
\end{tabular}


Fig. 2 Consistency of choices

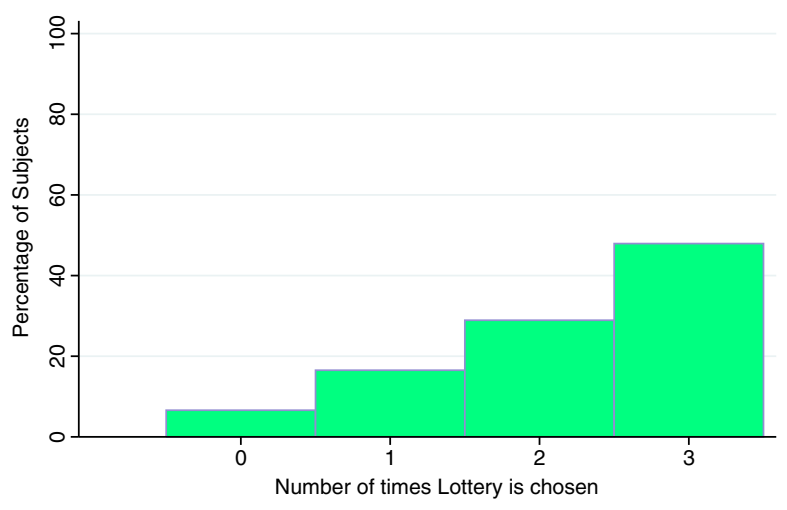

get a more detailed picture, Table 2 shows in which questions subjects chose the lottery rather than the corresponding allocation.

As we can see, $47.93 \%$ of the subjects always prefer to give a lottery rather than the corresponding allocation to the other subjects, whereas only $6.61 \%$ prefer the exact opposite. Moreover, $28.92 \%$ and $16.53 \%$ prefer the lottery to the allocation twice and once, respectively. Thus, we indeed observe a clear regularity in the preferences for the lottery over the corresponding allocation.

P2, P4, and P5 test whether the lotteries and corresponding allocations in P1, P3, and P7 are considered to be better or worse than the lottery that guarantees equality. Interestingly, we do not observe an overall preference for the lottery that guarantees equality. In P4 and P5 subjects clearly prefer to give the same as they will receive to the other subjects (signtest: $\mathrm{p}<0.001$, twosided). The percentages are $69.42 \%$, and $88.43 \%$, respectively. However, in P2 $69.42 \%$ of the subjects prefer to give the others the allocation rather than the same payoff as they themselves will receive. Overall, subjects prefer the lottery over the corresponding allocation no matter whether this allocation or lottery is considered to be better or worse than the lottery which would guarantee equality. In P6 subjects clearly prefer to give the same as they will receive to the other subjects (signtest: $\mathrm{p}<0.001$, two-sided), which is consistent with the findings in P5 and P7.

Table 2 Patterns in choices between lotteries and their corresponding allocations

\begin{tabular}{llllr}
\hline Lottery preferred & $\mathrm{P} 1$ & $\mathrm{P} 3$ & $\mathrm{P} 7$ & \% of subjects \\
\hline Always & $\mathrm{x}$ & $\mathrm{x}$ & $\mathrm{x}$ & $47.93 \%$ \\
Twice & $\mathrm{x}$ & $\mathrm{x}$ & & $4.96 \%$ \\
& $\mathrm{x}$ & & $\mathrm{x}$ & $13.22 \%$ \\
& & $\mathrm{x}$ & $\mathrm{x}$ & $10.74 \%$ \\
Once & $\mathrm{x}$ & & & $1.65 \%$ \\
& & $\mathrm{x}$ & & $4.13 \%$ \\
\% of subjects & $67.8 \%$ & $67.8 \%$ & $82.6 \%$ & \\
\hline
\end{tabular}


P8, P9, and P10 test whether subjects are concerned with the equality of allocations among other subjects. Subjects did not significantly prefer one allocation over the other in these questions, suggesting that they, on average, were not concerned with the equality of the allocation among other subjects.

Finally, in P11 and P12, the subjects preferred to give the others the highest possible outcome in $87.60 \%$ and $85.95 \%$ of the cases, which was highly significant. This illustrates that subjects are willing to maximize the payoff of others, even if this leads to being worse off than these other subjects. Thus, the results of the individual risk questions cannot be driven by subjects being purely selfish, which we will discuss further in Section 4.

Again, we found no significant influence of the demographic variables on the choices made by subjects.

\section{Interpretation and discussion}

\subsection{Further interpretation}

We will now further interpret the findings reported in Fig. 1 and Table 1. Overall, not many switches were observed in Fig. 1, suggesting that choices are not strongly affected by the payoffs and risks of others. One could argue that the subjects therefore do not care about the payoffs of others. This argument, however, is contradicted by the fact that at least $85 \%$ of the subjects chose to maximize others' payoffs in P11 and P12. These findings are in line with the results from the debriefings, where subjects had to indicate how they made their decisions. Subjects indicated having lexicographic preferences, whereby they first choose the best lottery for themselves, and only then care about the lotteries of others.

We will now investigate whether the few switches that are observed, though, do suggest consistent behavioral patterns. First, consider the Certainty questions. The interesting feature of the lotteries in these types of questions is that subjects can avoid the standard risk by choosing lottery 2, which gives them a certain payoff of 10 . On top of that, in C4 and C8 they can even avoid another type of risk by choosing lottery 2, namely the risk of facing an unequal allocation. Choosing lottery 1 in $\mathrm{C} 4$, could lead to inequality as the others will face the exact same lottery. Choosing lottery 1 in $\mathrm{C} 8$ would lead to inequality anyhow. Figure 1 shows that in C4 and C8 lottery 2 is significantly more chosen in comparison to the questions where the other subjects receive a certain payoff.

In C2 and C5, lottery 1 is significantly more chosen. In both these questions, subjects can never end up being worse off than other subjects. In C2 strict equality will arise no matter which lottery is chosen. In C5, the worst possible payoff for a subject in the risky lottery is the payoff that all other subjects receive. Choosing the risky lottery, therefore, will not lead to disadvantageous inequality in the sense of the decision maker being worst off. 
In $\mathrm{C} 1$, a subject will for sure face inequality by choosing lottery 2 , as he would then receive a payoff of 10 , whereas all others would receive a payoff of 16. A subject might therefore be induced to choose lottery 1 as there he still faces the chance of being better off than the other subjects. The certainty in the other subjects' payoff leads to a relatively higher choice of the risky lottery 1 .

In the MPS and Maximin questions certainty can never be assured, as no payoff is given for sure to the decision maker. Certainty in terms of equality can only be assured in MPS10 and MM3 where the other subjects receive the same outcome as the decision maker. The results of the MPS and Maximin do not show a clear choice pattern.

The results of the peer risk questions are striking. Subjects appear to have a strong preference for one allocation rule over the other. They prefer the lottery to the corresponding distribution. This result suggests that subjects are not willing to be held responsible for determining the allocation of payoffs. They would rather have fate determine the actual payoffs of the other subjects. In that sense, they are decision averse. Interestingly, we observe this preference irrespective of whether the other subjects face a higher, an equal or a lower expected value than the decision maker. However, we do observe significantly more subjects choosing the lottery when the expected value for the other subjects is lower than the expected value for the decision maker (signtest P1 vs P3: $p=0.001$, one-sided, and signtest P3 vs P7: $p=0.003$, one sided).

Two possible explanations can be given for the fact that in P4, P5 and P6 subjects prefer to give the same payoff to the others as they will receive themselves, while this preference is not present in P2. Subjects seem to be maximizing the expected values of the other subjects. However, this interpretation does not explain why we find a significant preference for 'the same payoff as you' in case where the expected values of all subjects are identical. This brings us to the second possible explanation. In all questions where subjects prefer to choose the same payoff as themselves for the other subjects, the lottery or allocation they would otherwise get contains the worst possible outcome in comparison to the lowest possible outcome in their own lottery. Maximizing the other subjects' worst possible outcome, therefore seems to be another plausible motive. Both motives are actually confirmed by the results found for P11 and P12. In these two questions the lottery which maximizes the other subjects' (worst possible) payoff is significantly more often chosen (signtest: $\mathrm{p}<0.001$ for both questions). Subjects are thus willing to maximize the (worst possible) payoff of others, even if this may lead to being worse off than these other subjects. In P11, 87.60\% and in P12, 85.95\% of the subjects behaved in this way.

\subsection{Discussion}

We are aware of three studies that are close in spirit to ours. Brennan et al. (2008) did an experiment in the spirit of our experimental design. They considered two lotteries: a risky and a sure one, which gives the expected payoff of the risky one for sure. Every subject was paired with another subject. 
The authors considered four allocation lotteries: (1) both subjects receive the lottery, (2) both subjects receive the sure payoff,(3) one subject receives the lottery and the other the sure payoff, and (4) the reverse. Then they elicited the willingness to pay (WTP) and the willingness to accept (WTA) of the decision maker for each of these allocation lotteries, given that the other player does not pay or receive anything. Thus, strictly speaking, in the WTA treatment the decision maker chooses between an allocation lottery and an allocation where he receives the WTA and his partner receives nothing. Therefore, in the choice the lottery of the other player is not kept fixed. When choosing (or determining the WTA or WTP) the player thus simultaneously determines his own and his partner's payoff. In the analysis of the results, though, Brennan et al. compare the WTP and WTA from the four allocation lotteries. In that sense their experiment is close in spirit to ours. Interestingly, Brennan et al. (2008) also find no significant effect of the risk of others on individual behavior.

Another experiment in the spirit of ours is Linde and Sonnemans (2009). Linde and Sonnemans studied whether risk attitudes depend on whether others receive more or less than the decision maker. They show that subjects are relatively more risk averse when they are guaranteed to earn less than their partner, though the vast majority of subjects behaves according to risk aversion. Linde and Sonnemans' study differs from ours in some important aspects. First, they only consider others' payoffs to be riskless. Second, their experiment includes a large proportion of questions where the decision maker simultaneously influences his own and the other's payoff. Third, subjects are randomly paired with one other subject in their study, while we consider all subjects in one session as one group. Fourth, each subject first had to play several Bertrand games against the subject he was paired with. Only after these Bertrand games did the subjects answer the questions in the spirit of our experimental design. Between the Bertrand games and the next questions every subject was shown the picture of his partner.

The experiment by Kroll and Davidovitz (2003) is in a similar spirit as our peer risk questions $\mathrm{P} 1, \mathrm{P} 3$, and $\mathrm{P} 7$ in the sense that it concerns allocation rules. They let children choose between two allocation lotteries. The first allocation lottery, which they call 'common game', would give the decision maker a particular lottery and the others would receive the same as the decision maker. In the second allocation, which they call 'individual game' the lottery was the same, but it was resolved for every subject independently. They found a significant preference for the first lottery. This finding predicts that C2, MPS10, and MM3 are perceived to be different than C4, MPS4, and MM7, respectively. We only find a significant switch in a particular direction between $\mathrm{C} 2$ and $\mathrm{C} 4$, though.

\section{Conclusion}

In order to examine how risks and payoffs of others influence risk attitudes, we conducted an experiment. The key feature of our experiment is to keep either 
the lottery of the decision maker or the lottery that others receive fixed, and to vary the other lottery. Then repeating the questions for a different fixed lottery allows us to explore risk attitudes in a social context. It allows us to analyze whether risk attitudes depend on the lotteries others face. Since the decision makers do not influence the payoffs of others in this context, choices cannot be driven by intentions, social pressure or reciprocity. Thus, our results are not confounded by reciprocity and fully reflect preferences over allocations.

The results show that risk attitudes are not so much affected by the risks others face. Since a large majority of the subjects did choose to maximize others' payoffs if this would not influence their own payoffs, we can nevertheless not conclude that they are purely selfish. Combined with the results from the debriefing, these results suggest that subjects have lexicographic social preferences whereby they first maximize their own utility and only then the utility of others. Striking is the finding that subjects prefer lotteries to their corresponding allocations, where risks are perfectly independent across subjects. This suggests that they prefer risks to be independent across members of the population rather than correlated. It also indicates that subjects prefer everybody to undergo the same procedure, thereby avoiding the possibility to be held responsible for bad outcomes of others.

Open Access This article is distributed under the terms of the Creative Commons Attribution Noncommercial License which permits any noncommercial use, distribution, and reproduction in any medium, provided the original author(s) and source are credited.

\section{Appendix A}

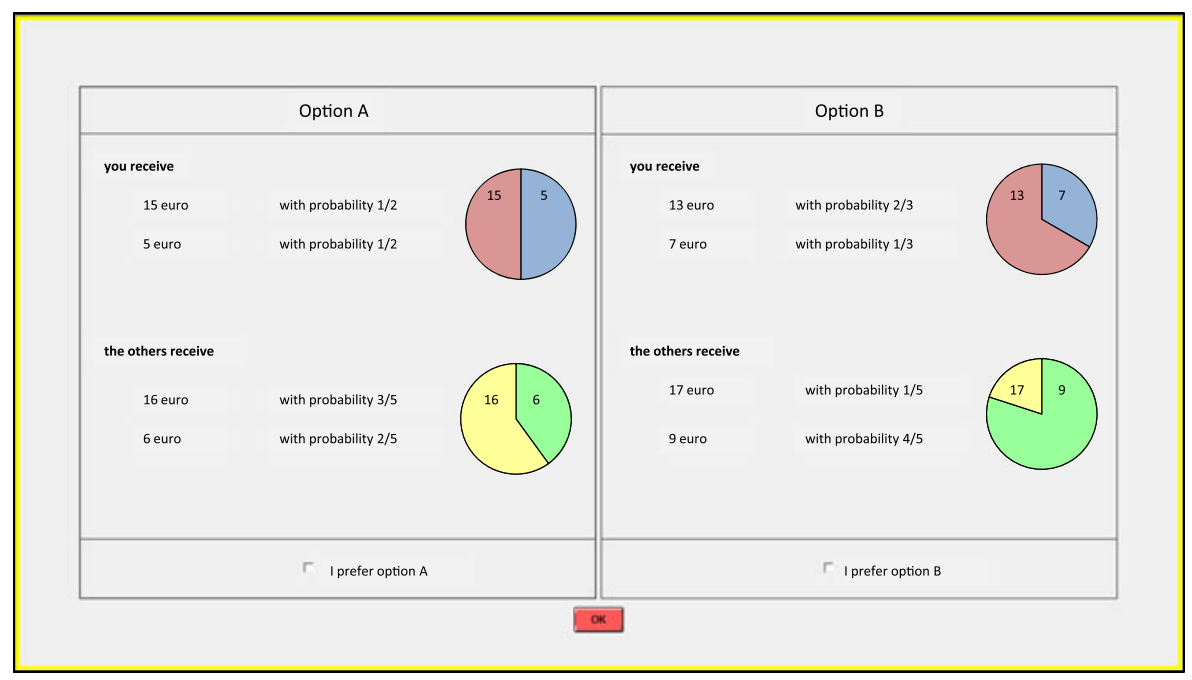

Fig. 3 Screenshot 
Table 3 Individual risk questions: certainty

\begin{tabular}{llll}
\hline Certainty & Lottery 1 & Lottery 2 & Lottery others \\
\hline C1 & $(30 \%: 23,70 \%: 3)$ & 10 & 16 \\
C2 & $(30 \%: 23,70 \%: 3)$ & 10 & same payoff as you \\
C3 & $(30 \%: 23,70 \%: 3)$ & 10 & $(20 \%: 25,80 \%: 5)$ \\
C4 & $(30 \%: 23,70 \%: 3)$ & 10 & same lottery as you \\
C5 & $(30 \%: 23,70 \%: 3)$ & 10 & 3 \\
C6 & $(30 \%: 23,70 \%: 3)$ & 10 & $(50 \%: 15,50 \% 5)$ \\
C7 & $(30 \%: 23,70 \%: 3)$ & 10 & 15 for $50 \%$ of subjects \\
& & & 5 for $50 \%$ of subjects \\
C8 & $(30 \%: 23,70 \%: 3)$ & 10 & 10 \\
\hline
\end{tabular}

Note that the expected value of lottery 1 is 9 , while the expected value of lottery 2 is 10 . We chose this expected value of 9 , because we expected the social context to have a strong impact on risk attitudes. Thus, we expected that subjects would be risk seeking in this context, so as to still be able to get more than the other subjects in at least some instances. As the results show, though, the impact of the social context on choices appeared not to be that strong

Table 4 Individual risk questions: Mean Preserving Spread

\begin{tabular}{llll}
\hline $\begin{array}{l}\text { Mean Preserving } \\
\text { Spread }\end{array}$ & Lottery 1 & Lottery 2 & Lottery others \\
\hline MPS1 & $(40 \%: 13,60 \%: 8)$ & $(50 \%: 20,50 \%: 0)$ & 10 \\
MPS2 & $(40 \%: 13,60 \%: 8)$ & $(50 \%: 20,50 \%: 0)$ & 13 \\
MPS3 & $(40 \%: 13,60 \%: 8)$ & $(50 \%: 20,50 \%: 0)$ & $(50 \%: 25,50 \%: 5)$ \\
MPS4 & $(40 \%: 13,60 \%: 8)$ & $(50 \%: 20,50 \%: 0)$ & same lottery as you \\
MPS5 & $(40 \%: 13,60 \%: 8)$ & $(50 \%: 20,50 \%: 0)$ & 20 \\
MPS6 & $(40 \%: 13,60 \%: 8)$ & $(50 \%: 20,50 \%: 0)$ & 8 \\
MPS7 & $(40 \%: 13,60 \%: 8)$ & $(50 \%: 20,50 \%: 0)$ & 0 \\
MPS8 & $(40 \%: 13,60 \%: 8)$ & $(50 \%: 20,50 \%: 0)$ & $(20 \%: 20,80 \%: 0)$ \\
MPS9 & $(40 \%: 13,60 \%: 8)$ & $(50 \%: 20,50 \%: 0)$ & 20 for $20 \%$ of subjects \\
MPS10 & & & 0 for $80 \%$ of subjects \\
\hline
\end{tabular}

Table 5 Individual risk questions: Maximin

\begin{tabular}{llll}
\hline & Lottery 1 & Lottery 2 & Lottery others \\
\hline $\begin{array}{l}\text { Maximin } \\
\text { MM1 }\end{array}$ & $(80 \%: 12,20 \%: 2)$ & $(80 \%: 7,20 \%: 22)$ & $(80 \%: 12,20 \%: 2)$ \\
MM2 & $(80 \%: 12,20 \%: 2)$ & $(80 \%: 7,20 \%: 22)$ & $(80 \%: 7,20 \%: 22)$ \\
MM3 & $(80 \%: 12,20 \%: 2)$ & $(80 \%: 7,20 \%: 22)$ & same payoff as you \\
MM4 & $(80 \%: 12,20 \%: 2)$ & $(80 \%: 7,20 \%: 22)$ & 12 for $80 \%$ of subjects \\
& & 2 for $20 \%$ of subjects \\
MM5 & $(80 \%: 12,20 \%: 2)$ & $(80 \%: 7,20 \%: 22)$ & 7 for $80 \%$ of subjects \\
MM6 & $(80 \%: 12,20 \%: 2)$ & $(80 \%: 7,20 \%: 22)$ & 10 \\
MM7 & $(80 \%: 12,20 \%: 2)$ & $(80 \%: 7,20 \%: 22)$ & same lottery as you \\
MM8 & $(80 \%: 12,20 \%: 2)$ & $(80 \%: 7,20 \%: 22)$ & $(50 \%: 11,50 \%: 9)$ \\
Maximin High & & & \\
Stakes & & $(40 \%: 13,60 \%: 8)$ & $(33 \%: 33,67 \%: 0)$ \\
MMH1 & $(20 \%: 60,80 \%: 0)$ & $(40 \%: 13,60 \%: 8)$ & 11 \\
MMH2 & $(20 \%: 60,80 \%: 0)$ & & \\
\hline
\end{tabular}


Table 6 Peer risk questions

\begin{tabular}{|c|c|c|c|}
\hline & You & Others 1 & Others 2 \\
\hline P1 & $(40 \%: 13,60 \%: 8)$ & $(30 \%: 20,70 \%: 10)$ & $\begin{array}{l}20 \text { for } 30 \% \text { of subjects } \\
10 \text { for } 70 \% \text { of subjects }\end{array}$ \\
\hline $\mathrm{P} 2$ & $(40 \%: 13,60 \%: 8)$ & same payoff as you & $\begin{array}{l}20 \text { for } 30 \% \text { of subjects } \\
10 \text { for } 70 \% \text { of subjects }\end{array}$ \\
\hline P3 & $(30 \%: 17,70 \%: 7)$ & $(50 \%: 15,50 \%: 5)$ & $\begin{array}{l}15 \text { for } 50 \% \text { of subjects } \\
5 \text { for } 50 \% \text { of subjects }\end{array}$ \\
\hline P4 & $(30 \%: 17,70 \%: 7)$ & $(50 \%: 15,50 \%: 5)$ & same payoff as you \\
\hline P5 & $(50 \%: 16,50 \%: 4)$ & $(20 \%: 20,80 \%: 0)$ & same payoff as you \\
\hline P6 & $(50 \%: 16,50 \%: 4)$ & same payoff as you & $\begin{array}{l}20 \text { for } 20 \% \text { of subjects } \\
0 \text { for } 80 \% \text { of subjects }\end{array}$ \\
\hline P7 & $(50 \%: 16,50 \%: 4)$ & $(20 \%: 20,80 \%: 0)$ & $\begin{array}{l}20 \text { for } 20 \% \text { of subjects } \\
0 \text { for } 80 \% \text { of subjects }\end{array}$ \\
\hline P8 & $(20 \%: 20,80 \%: 8)$ & $\begin{array}{l}13 \text { for } 40 \% \text { of subjects } \\
8 \text { for } 60 \% \text { of subjects }\end{array}$ & $\begin{array}{c}14 \text { for } 20 \% \text { of subjects } \\
12 \text { for } 20 \% \text { of subjects } \\
10 \text { for } 30 \% \text { of subjects } \\
6 \text { for } 30 \% \text { of subjects }\end{array}$ \\
\hline P9 & $(20 \%: 20,80 \%: 8)$ & $\begin{array}{l}13 \text { for } 40 \% \text { of subjects } \\
8 \text { for } 60 \% \text { of subjects }\end{array}$ & $\begin{array}{l}13 \text { for } 40 \% \text { of subjects } \\
10 \text { for } 30 \% \text { of subjects } \\
6 \text { for } 30 \% \text { of subjects }\end{array}$ \\
\hline $\mathrm{P} 10$ & $(20 \%: 20,80 \%: 8)$ & $\begin{array}{l}13 \text { for } 40 \% \text { of subjects } \\
8 \text { for } 60 \% \text { of subjects }\end{array}$ & $\begin{array}{l}14 \text { for } 20 \% \text { of subjects } \\
12 \text { for } 20 \% \text { of subjects } \\
8 \text { for } 60 \% \text { of subjects }\end{array}$ \\
\hline P11 & $(40 \%: 13,60 \%: 8)$ & 13 & 8 \\
\hline $\mathrm{P} 12$ & 10 & 13 & 8 \\
\hline
\end{tabular}

Table 7 Percentage choice Lottery 1 across different questions

\begin{tabular}{|c|c|c|c|c|c|}
\hline \multicolumn{2}{|l|}{ Certainty } & \multicolumn{2}{|c|}{ Mean Preserving Spread } & \multicolumn{2}{|l|}{ Maximin } \\
\hline Question & Percentage & Question & Percentage & Question & Percentage \\
\hline$\overline{\mathrm{C} 1}$ & $22.3 \%$ & MPS1 & $83.5 \%$ & MM1 & $28.1 \%$ \\
\hline $\mathrm{C} 2$ & $23.1 \%$ & MPS2 & $85.1 \%$ & MM2 & $24.8 \%$ \\
\hline $\mathrm{C} 3$ & $20.7 \%$ & MPS3 & $86.0 \%$ & MM3 & $31.4 \%$ \\
\hline $\mathrm{C} 4$ & $16.5 \%$ & MPS4 & $83.5 \%$ & MM4 & $27.3 \%$ \\
\hline C5 & $24.0 \%$ & MPS5 & $81.8 \%$ & MM5 & $21.5 \%$ \\
\hline C6 & $20.7 \%$ & MPS6 & $80.2 \%$ & MM6 & $22.3 \%$ \\
\hline C7 & $19.8 \%$ & MPS7 & $78.5 \%$ & MM7 & $28.1 \%$ \\
\hline \multirow[t]{3}{*}{$\mathrm{C} 8$} & $14.9 \%$ & MPS8 & $78.5 \%$ & MM8 & $28.1 \%$ \\
\hline & & MPS9 & $82.6 \%$ & MMH1 & $55.4 \%$ \\
\hline & & MPS10 & $83.5 \%$ & MMH2 & $53.7 \%$ \\
\hline
\end{tabular}

Table 8 Percentage choice Others 1 across different questions

\begin{tabular}{llll}
\hline Question & Percentage & Question & Percentage \\
\hline P1 & $67.8 \%$ & P8 & $47.9 \%$ \\
P2 & $30.6 \%$ & P9 & $52.1 \%$ \\
P3 & $67.8 \%$ & P10 & $47.1 \%$ \\
P4 & $30.6 \%$ & P11 & $87.6 \%$ \\
P5 & $11.6 \%$ & P12 & $86.0 \%$ \\
P6 & $87.6 \%$ & & \\
P7 & $82.6 \%$ & & \\
\hline
\end{tabular}




\section{Appendix B: Instructions}

\section{Introduction}

Welcome to this decision-making experiment. In this experiment you can earn money. How much you earn depends on your decisions and the decisions of other participants and random events. At the end of the experiment your earnings will be paid out privately and confidentially in cash.

It is important that you have a good understanding of the rules in the experiment. Therefore, please read these instructions carefully. In order to check that the instructions are clear to you, you will be asked a few questions at the end of the instructions. The experiment will start only after everybody has correctly answered those questions. At the end of the experiment you will be asked to fill in a short questionnaire. Thereafter you will receive your earnings.

During the whole experiment, you are not allowed to communicate with other participants.

If you have a question, please raise your hand. We will then come to you and answer your question in private.

\section{Explanation of experiment}

During this experiment there are eleven participants, which means that there are ten other participants. The other participants answer the same questions as you do, only in a different order.

The experiment consists of 40 questions. In each question you will be asked to choose between two allocations of lotteries for the participants in this experiment. Your choices will be anonymous. There is no wrong or right answer. We are only interested in your own preferences. During the experiment, you will not receive any information about the choices of the other participants. They will also not receive any information about your choices.

You will encounter three types of allocations. We will now explain these three types of allocations. Note that in each question you will have to choose between two allocations.

Independent lotteries In the first type of allocation everyone receives a lottery. You may receive a different lottery than all the other participants, but all other participants receive a common lottery. An example of such an allocation is as follows

\section{Allocation I}

You receive

17 euro with probability $1 / 5$

18 euro with probability $4 / 5$

The others receive

15 euro with probability $2 / 5$

19 euro with probability $3 / 5$ 
In this allocation a lottery is played for you, which yields 17 euro with probability $1 / 5$ and 18 euro with probability $4 / 5$. For each other participant a lottery is played, which yields 15 euro with probability $2 / 5$ and 19 euro with probability $3 / 5$. The lotteries of different participants are thus independent and do not necessarily yield the same payoff. This means that when your lottery turns out to yield 17 euro, this does not increase or decrease the probability of another person getting 15 euro. Moreover, if the lottery of one other participant, called participant $\mathrm{A}$, turns out to yield 15 euro, then the probability that another participant, called participant $\mathrm{B}$, also gets 15 euro remains 2/5. Participant $\mathrm{B}$ does not necessarily then also receive 15 euro. For him the lottery is also played, and he also gets 15 euro with the probability $2 / 5$. Thus the lottery is played for each player separately, not only once for all "others" at the same time.

Let's consider another allocation:

\begin{tabular}{|ll|}
\hline $\begin{array}{l}\text { Allocation II } \\
\text { You receive }\end{array}$ & 17 euro with probability $1 / 5$ \\
& 18 euro with probability $4 / 5$ \\
The others receive & \\
& 17 euro with probability $1 / 5$ \\
& 18 euro with probability $4 / 5$ \\
\hline
\end{tabular}

In this allocation everybody receives the same lottery. Depending on the realizations of the lotteries, it is likely that not everybody will receive the same payoff, because the lottery is played for each player separately, not only once for all "others" at the same time.

Others receive the same as you In the second type of allocation you receive a lottery and all other participants will receive the same payoff as you. An example is as follows:

\begin{tabular}{|lc|}
\hline $\begin{array}{l}\text { Allocation III } \\
\text { You receive }\end{array}$ & $\begin{array}{l}10 \text { euro with probability } 1 / 5 \\
18 \text { euro with probability } 4 / 5\end{array}$ \\
The others receive & the same as you \\
& \\
\hline
\end{tabular}

In this lottery you receive 10 euro with probability $1 / 5$ and 18 euro otherwise. If it turns out that you receive 10 euro, then all other participants will also receive 10 euro. If it turns out that you receive 18 euro, then all other participants will also receive 18 euro. In this sense your outcome will determine what the others get. 
Others receive different payoffs with certainty In the third type of allocation you receive a lottery and one part of the other participants gets one payoff and the other participants get another payoff for sure. Consider the following example:

\begin{tabular}{|lc|}
\hline $\begin{array}{l}\text { Allocation IV } \\
\text { You receive }\end{array}$ & $\begin{array}{c}\text { 25 euro with probability } 1 / 5 \\
8 \text { euro with probability } 4 / 5\end{array}$ \\
The others receive & \\
& 3 persons receive 15 euro \\
& 7 persons receive 19 euro \\
\hline
\end{tabular}

In this allocation you receive the lottery, which yields a payoff of 25 euro with probability $1 / 5$ and a payoff of 8 euro with probability $4 / 5$. From the other participants the computer will randomly select 3 people who will receive 15 euro and the others will receive 19 euro.

During the experiment we will repeatedly ask you to make a choice between two allocations. The screen you will see during the experiment looks as follows.

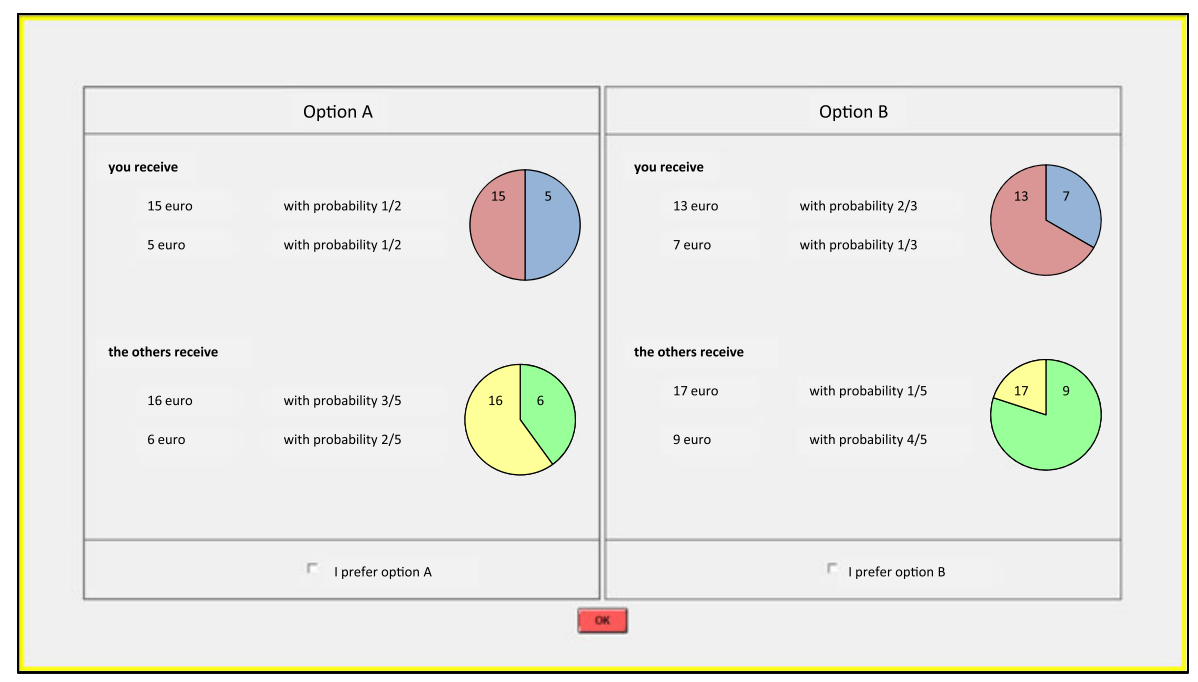

In the two boxes you see two different allocations, called option $\mathrm{A}$ and option B, from which you have to choose. The circles show a graphical representation of the corresponding allocations. After selecting one of the two allocations, you can press the "OK" button.

The first 3 questions will be "practice questions". The next questions all may determine your payoff at the end of this experiment. At the end of the experiment the computer will select one person out of the 11 participants 
at random. From that selected person one of the questions will randomly be selected and played out for real money, to determine the payoff of all participants. Note that this does not mean that the others will not receive anything. If you are the one selected, one of the questions you answered will be randomly selected and your chosen lottery will be played for you. Afterwards, the option you chose in that question will also be used to calculate the payoff of the others by playing the allocation you chose for them. The person who is selected thus determines the payoffs for all participants.

Thus, every time you answer a question, keep in mind that this question may be the one that will determine your payoff and the payoffs of the others in the end. Every allocation we describe may be the one you and the other participants really end up with.

Everybody will be paid his or her payoff from the experiment plus four euro for showing up.

\section{References}

Bohnet, I., Greig, F., Herrmann, B., \& Zeckhauser, R. (2008). Betrayal aversion. American Economic Review, 98, 294-310.

Bohnet, I., \& Zeckhauser, R. (2004). Trust, risk, and betrayal. Journal of Economic Behavior and Organization, 55, 467-84.

Boles, T. L., \& Messick, D. M. (1995). A reverse outcome bias: The influence of multiple reference points on the evaluation of outcomes and decisions. Organizational Behavior and Human Decision Processes, 61, 262-275.

Bolton, G. E., Brandts, J., \& Ockenfels, A. (2005). Fair procedures: Evidence from games involving lotteries. Economic Journal, 115, 1054-1076.

Bolton, G. E., \& Ockenfels, A. (2010). Betrayal aversion: Evidence from Brazil, China, Oman, Switzerland, Turkey, and the United States: Comment. American Economic Review, 100, 628-33.

Brennan, G., González, L. G., Güth, W., \& Levati, M. V. (2008). Attitudes toward private and collective risk in individual and strategic choice situations. Journal of Economic Behavior and Organization, 67, 253-262.

Broome, J. R. (1982). Equity in risk bearing. Operations Research, 30, 412-414.

Broome, J. R. (1984). Selecting people randomly. Ethics, 95, 38-55.

Charness, G., \& Rabin, M. (2002). Understanding social preferences with simple tests. Quarterly Journal of Economics, 117, 817-869.

Christakis, N. A., \& Fowler, J. H. (2007). The spread of obesity in a large social network over 32 years. New England Journal of Medicine, 357, 370-379.

Fehr, E., \& Schmidt, K. (2002). Theories of fairness and reciprocity-evidence and economic applications. In M. Dewatripont, L. Hansen, \& St. Turnovsky (Eds.), Advances in economics and econometrics—8th world congress, econometric society monographs. Cambridge: Cambridge University Press.

Fishburn, P. C. (1984). Equity axioms for public risks. Operations Research, 32, 901-908.

Fischbacher, U. (2007). z-Tree: Zurich toolbox for ready-made economic experiments. Experimental Economics, 10, 171-178.

Galí, J. (1994). Keeping up with the Joneses: Consumption externalities, portfolio choice, and asset prices. Journal of Money, Credit, and Banking, 26, 1-8.

Hammerton, M., Jones-Lee, M. W., \& Abbott, V. (1982). Equity and public risk: Some empirical results. Operations Research, 30, 203-207.

Kahneman, D., \& Tversky, A. (1979). Prospect theory: An analysis of decision under risk. Econometrica, 47, 263-291. 
Karni, E., Salmon, T., \& Sopher, B. (2008). Individual sense of fairness: An experimental study. Experimental Economics, 11, 174-189.

Keeney, R. L. (1980). Utility functions for equity and public risk. Management Science, 26, 345353.

Keller, L. R., \& Sarin, R. K. (1988). Equity in social risk: Some empirical observations. Risk Analysis, 8, 135-146.

Kroll, Y., \& Davidovitz, L. (2003). Inequality aversion versus risk aversion. Economica, 70, 19-29.

Linde, J., \& Sonnemans, J. (2009). Social comparison and risky choices. Working Paper.

Sebald, A. (2007). Procedural concerns in psychological games. Working Paper.

Shiller, R. J. (2008). The subprime solution: How today's global financial crisis happened, and what to do about it. Princeton, New Jersey: Princeton University Press.

Sobel, J. (2005). Interdependent preferences and reciprocity. Journal of Economic Literature, 93 , 392-436.

Trautmann, S. T. (2009). A tractable model of process fairness under risk. Journal of Economic Psychology, 30, 803-813. 